\title{
The Influence of Selective Laser Melting Parameters on Density and Mechanical Properties of AlSi10Mg
}

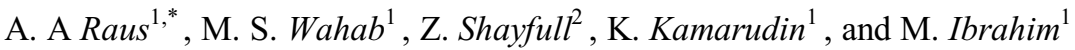 \\ ${ }^{1}$ Universiti Tun Hussein Onn Malaysia, Parit Raja, Batu Pahat, Johor, Malaysia \\ ${ }^{2}$ Green Design and Manufacture Research Group, Center of Excellence Geopolymer and Green \\ Technology (CEGeoGTech), Universiti Malaysia Perlis, 01000 Kangar, Perlis, Malaysia.
}

\begin{abstract}
Selective Laser Melting (SLM) is one of the most effective powder bed technique in the additive Manufacturing (AM) which able to fabricate functional metal parts directly from 3D Computer Aided Design (CAD) file data. In this paper, the influence of SLM parameters, such as laser power, scanning speed and hatching distance on the density of AlSi10Mg samples are investigated using one factor at a time (OFAT). Furthermore, the optimum results are used to fabricate samples for hardness, tensile strength, and impact toughness test. It is revealed that AlSi10Mg parts fabricated by SLM achieving the best density of $99.13 \%$ at the value of 350 watts laser power, $1650 \mathrm{~mm} / \mathrm{s}$ scanning speed and hatching distance $0.13 \mathrm{~mm}$, whereby resulted comparable and even better mechanical properties to those of conventionally HDPC A360F and HDPC A360T6 alloys although without any comprehensive post processing methods.
\end{abstract}

\section{Introduction}

Selective Laser Melting (SLM) is considerably one of the sufficient technique in the additive Manufacturing (AM) procedure in which a component is fabricated with a layer by layer technique through melting the top surface of a powder bed with a high intensity laser according to sliced 3D Computer Aided Design (CAD) data. Thin layers of material are spread intricately and stacked on the top of the building platform. A laser beam then melts and fuse the layer of powder metal, referring to the generated slice. After fabricating a layer was completed, the build piston will lower down the build platform and the following layer of powder is spread. The fabrication process repetitions continue from bottom to top until the part is completed [1-4]. The SLM process is controlled by the set of parameters listed in Table 1 that has a major influence on the quality of the final part [5]. The foremost build parameters involved in the process are laser power, hatch spacing, scanning speed, and layer thickness.

\footnotetext{
* Corresponding author: gd150034@siswa.uthm.edu.my
} 
Table 1. Controlling parameters in SLM process [5]

\begin{tabular}{|c|c|c|c|}
\hline \multicolumn{4}{|c|}{ Process Parameters } \\
\hline \begin{tabular}{ll}
\multicolumn{2}{l}{ Laser-related } \\
- & Laser \\
& power $(w a t t)$ \\
- & Spot Size $(\mu \mathrm{m})$ \\
- & Pulse \\
& Duration $(\mu \mathrm{s})$ \\
- & Pulse \\
& frequency $(\mathrm{Hz})$
\end{tabular} & 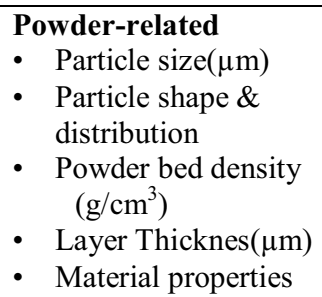 & 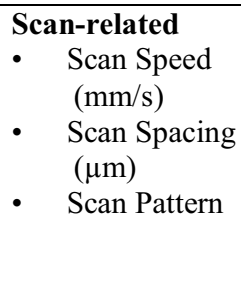 & $\begin{array}{l}\text { Temperature-related } \\
\text { - } \quad \text { Powder bed } \\
\quad \text { temperature }\left({ }^{\circ} \mathrm{C}\right) \\
\text { - } \quad \text { Powder feed } \\
\text { temperature }\left({ }^{\circ} \mathrm{C}\right) \\
\text { - Temperature } \\
\quad \text { uniformity }\left({ }^{\circ} \mathrm{C}\right)\end{array}$ \\
\hline
\end{tabular}

Besides the influence of processing parameters, powder characteristics are of significant concern. The shape, size, particle distribution and powder chemical composition have a strong effect on the melting and fusing process. Powders with low oxygen, content high flow rate and high packing density are preferred [6-9]

Aluminium-Silicon alloys are very light metal and owned a high strength, good weld ability and exceptional corrosion resistance. Due to their attractive combination of mechanical properties and high thermal conductivity, Al-Si alloys have been used in many industrial applications such as aerospace, automotive, and moulding industries [3,10-13]. By adding magnesium in aluminium-silicon alloys will increase the mechanical properties and improved the ductility and modulus of elasticity properties. Hence AlSi10Mg contains 0.3 to $0.5 \mathrm{wt} \% \mathrm{Mg}$, it is harden able through $\mathrm{T} 6$ cycle of solution annealing, quenching and age hardening heat treatment process to improve the mechanical properties [14-15].

The main goal of this paper is to investigate the density and mechanical properties such as hardness, tensile strength and impact toughness of AlSi10Mg samples fabricated by SLM and compare those properties to the high pressure die cast (HDPC) A360 alloy. The results will be used to predict and to facilitate the manufacturing process for mould fabrication.

\section{Experimental works}

The SLM system SLM 125 HL (SLM Solutions) as shown in Figure 1(a), was used to manufacture all samples in this study. The machine system is equipped with a 400 watt fibre laser , $80 \mu \mathrm{m}$ laser beam diameter and has a building chamber of $125 \mathrm{~mm} \times 125 \mathrm{~mm} \times$ $125 \mathrm{~mm}$ as shown in Figure 1(b). Argon is used as an inert gas in the building chamber. The stripe scanning strategy with $45^{\circ}$ orientation and $90^{\circ}$ rotated incrementally on the next layer was used. The platform building was heated at $150{ }^{\circ} \mathrm{C}$ to avoid the build samples from warping due to non-uniform thermal expansion at elevated temperature. Constant thickness layer at $30 \mu \mathrm{m}$ has been set by lowering the build platform. An aluminium platform is placed on the building platform (x-y table) and levelled. 


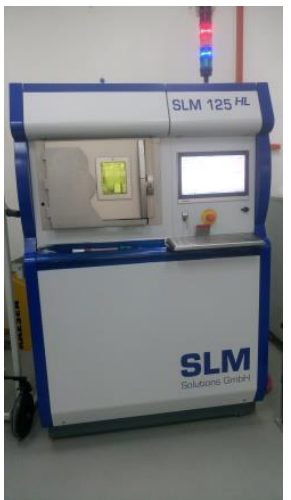

(a)

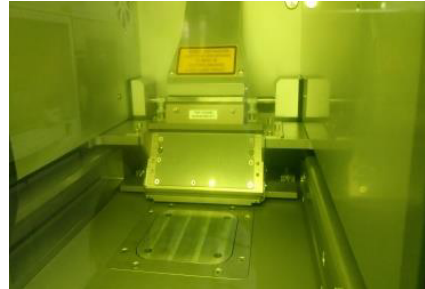

(b)

Fig. 1. (a) SLM 125HL 20121213-EN, (b) Build chamber SLM system SLM 125 HL

The AlSi10Mg in powder form having sieving powder of 63 micron, a loose density of $7.68 \mathrm{~g} / \mathrm{cm}^{3}$ and chemical composition as shown in Table 2 supplied from the LPW Technology Limited UK.

Table 2. Chemical composition of the investigated AlSi10Mg alloy (wt. \%).

\begin{tabular}{|c|c|c|c|c|c|c|c|c|c|}
\hline $\mathbf{S i}$ & $\mathbf{F e}$ & $\mathbf{M n}$ & $\mathbf{M g}$ & $\mathbf{N i}$ & $\mathbf{Z n}$ & $\mathbf{P b}$ & $\mathbf{S n}$ & $\mathbf{T i}$ & $\mathbf{A l}$ \\
\hline 9.92 & 0.137 & 0.004 & 0.291 & 0.004 & 0.001 & 0.004 & 0.003 & 0.006 & Balance \\
\hline
\end{tabular}

The samples $10 \mathrm{~mm} \times 10 \mathrm{~mm} \times 10 \mathrm{~mm}$ in cubic shape were fabricated in $3 \times 11$ matrix by varying one factor (laser power/scanning speed/hatching distance) and the remaining two parameters constant at the values shown in Table 3 to find the relative density by using Archimedes method.

Table 3. Parameters selection using OFAT for Selective Laser Sintering Machine

\begin{tabular}{|c|c|c|c|c|}
\hline Row No. & Laser Power & Scanning speed & Hatching distance & No. of Sample \\
\hline 1 & $320-380 \mathrm{~W}$ & $1650 \mathrm{~mm} / \mathrm{s}$ & $0.13 \mathrm{~mm}$ & 11 \\
\hline 2 & $350 \mathrm{~W}$ & $1550-1750 \mathrm{~mm} / \mathrm{s}$ & $0.13 \mathrm{~mm}$ & 11 \\
\hline 3 & $350 \mathrm{~W}$ & $1650 \mathrm{~mm} / \mathrm{s}$ & $0.10-0.15 \mathrm{~mm}$ & 11 \\
\hline
\end{tabular}

In order to fabricate the mechanical properties test samples in optimum condition, the experiment was conducted using the optimised parameters of the density test. A laser power of 350 watt scan speed of $1650 \mathrm{~mm} / \mathrm{s}$ and a hatching distance of $0.13 \mathrm{~mm}$ was used to fabricate the samples as shown in Figure 2.

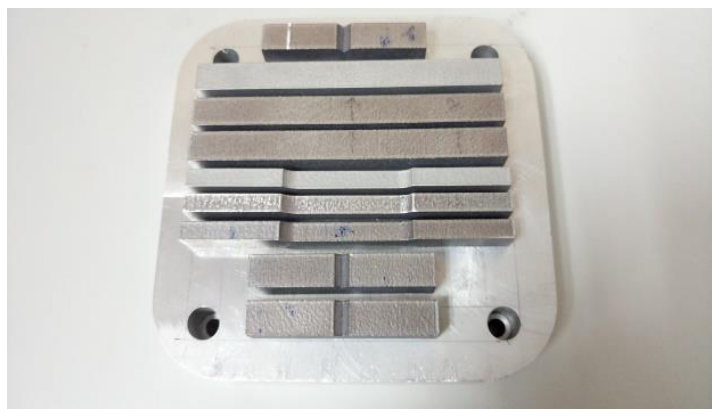

Fig. 2. The arrangement of samples on the SLM platform 
To determine the mechanical properties, hardness, tensile, and Charpy impact tests were performed. The value of the hardness tests was measured using Shimadzu HMV-2T E under the load of $2.942 \mathrm{~N}$ (HV0.3). The measurement was taken from the top and side surfaces at 9 different locations for general characterisation of the microstructure as shown in Figure 3 (a) and (b).

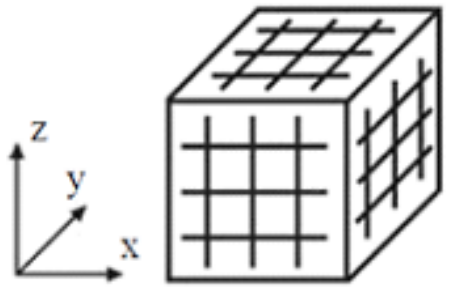

(a)

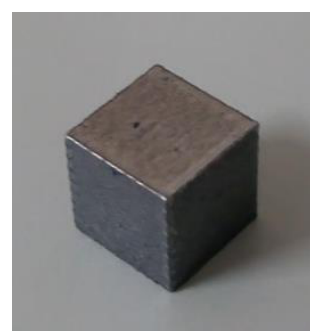

(b)

Fig. 3. (a) Indication of different locations for hardness test on blocks; (b) (10x10x10)mm cube produced by SLM for hardness test.

ASTM E8 standard tensile test samples with the $25 \mathrm{~mm}$ gauge length were built on the platform in the $\mathrm{x}-\mathrm{Z}$ axis. Precision machining and polishing by abrasive papers were carry out on the gage length to provide the notch effect. A Gotech testing machine with $0.5 \mathrm{~mm} / \mathrm{s}$ test speed was used to measure the tensile strength. Samples for transverse rupture strength test were prepared according to the ASTM E23 Type A [16].

\section{Results and discussion}

\subsection{Morphology of AISi10Mg powder particles}

Figure 4 shows the Field Emission Scanning Electron Microscope (FESEM, JSM-7600F) micrograph of AlSi10Mg powder as in recieved form. The AlSi10Mg particles are not spherical and size ranges from 5 to $80 \mu \mathrm{m}$. The appearance of the particles is irregular morphology, with many small irregular satellite particles agglomerated to bigger particles creating some clusters of about 60 to $90 \mu \mathrm{m}$, and this could be detrimental for the final density of the SLM parts, considering that the layer thickness employed in this research is of $30 \mu \mathrm{m}$. Regardless of the irregular powder morphology, the powder had an acceptable flowability and Hauser's ratio for SLM. 


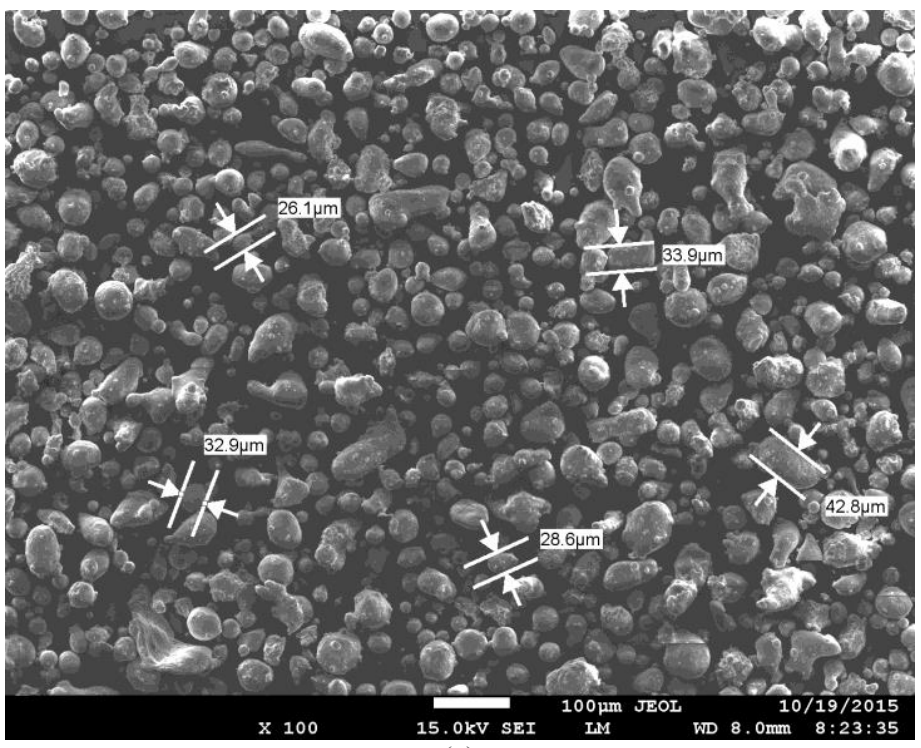

(a)

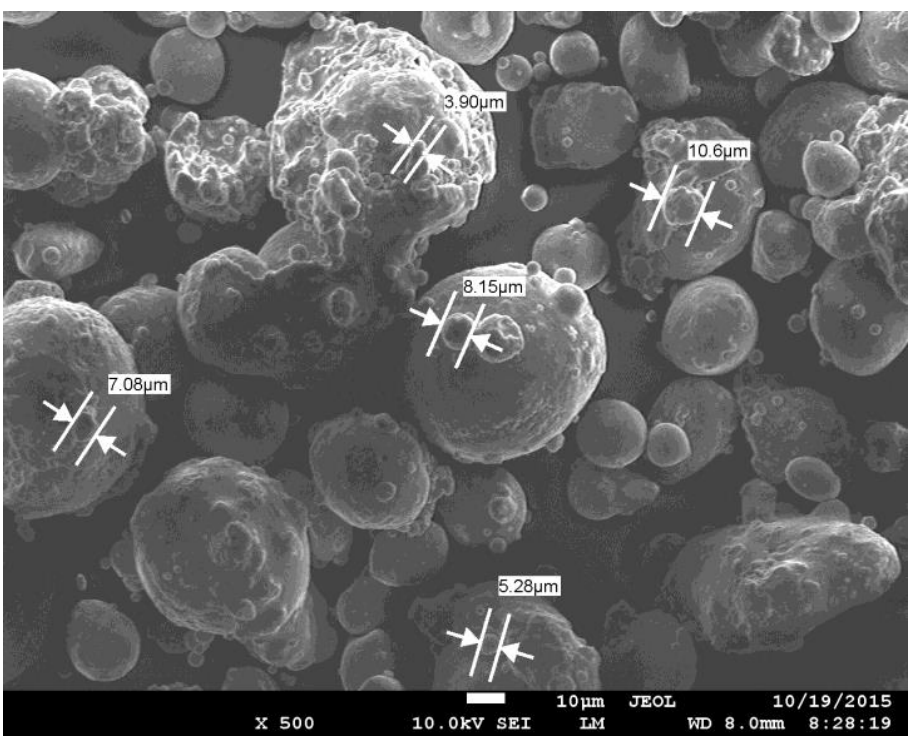

(b)

Fig. 4. Shows the Field Emission Scanning Electron Microscope (FESEM, JSM-7600F) micrograph of AlSi10Mg powder (a) x100, (b) x500

\subsection{Density Study}

In this study the Archimedes standard method was used to determine the density of the SLM processed AlSil0Mg samples and compared with the distilled water in the pycnometer. Table 4 and Figure 4 shows the values for measuring density using an OFAT technique on laser power, scanning speed and Hatching distance. 
Table 4. Density measurement by Archimedes method

\begin{tabular}{|c|c|c|c|c|c|}
\hline Parameter & $\begin{array}{c}\text { Density } \\
\# 1\end{array}$ & $\begin{array}{c}\text { Density } \\
\# 2\end{array}$ & $\begin{array}{c}\text { Density } \\
\# 3\end{array}$ & $\begin{array}{c}\text { Density } \\
\# 4\end{array}$ & $\begin{array}{c}\text { Density } \\
\# 5\end{array}$ \\
\hline $320-380 \mathrm{~W}$ & $98.70 \%$ & $99.03 \%$ & $98.91 \%$ & $98.88 \%$ & $99.07 \%$ \\
\hline $\begin{array}{c}1550-1750 \\
\mathrm{~mm} / \mathrm{s}\end{array}$ & $98.88 \%$ & $99.05 \%$ & $98.96 \%$ & $99.04 \%$ & $99.11 \%$ \\
\hline $0.10-0.15 \mathrm{~mm}$ & $98.92 \%$ & $98.84 \%$ & $98.78 \%$ & $99.11 \%$ & $99.13 \%$ \\
\hline
\end{tabular}

\begin{tabular}{|c|c|c|c|c|c|}
\hline $\begin{array}{c}\text { Density } \\
\#-6\end{array}$ & $\begin{array}{c}\text { Density } \\
\# 7\end{array}$ & $\begin{array}{c}\text { Density } \\
\# 8\end{array}$ & $\begin{array}{c}\text { Density } \\
\# 9\end{array}$ & $\begin{array}{c}\text { Density } \\
\# 10\end{array}$ & $\begin{array}{c}\text { Density } \\
\# 11\end{array}$ \\
\hline $98.88 \%$ & $98.83 \%$ & $98.85 \%$ & $98.67 \%$ & $98.56 \%$ & $98.54 \%$ \\
\hline $99.00 \%$ & $98.86 \%$ & $99.08 \%$ & $98.93 \%$ & $98.94 \%$ & $98.87 \%$ \\
\hline $99.10 \%$ & $99.04 \%$ & $98.90 \%$ & $98.79 \%$ & $98.78 \%$ & $98.65 \%$ \\
\hline
\end{tabular}

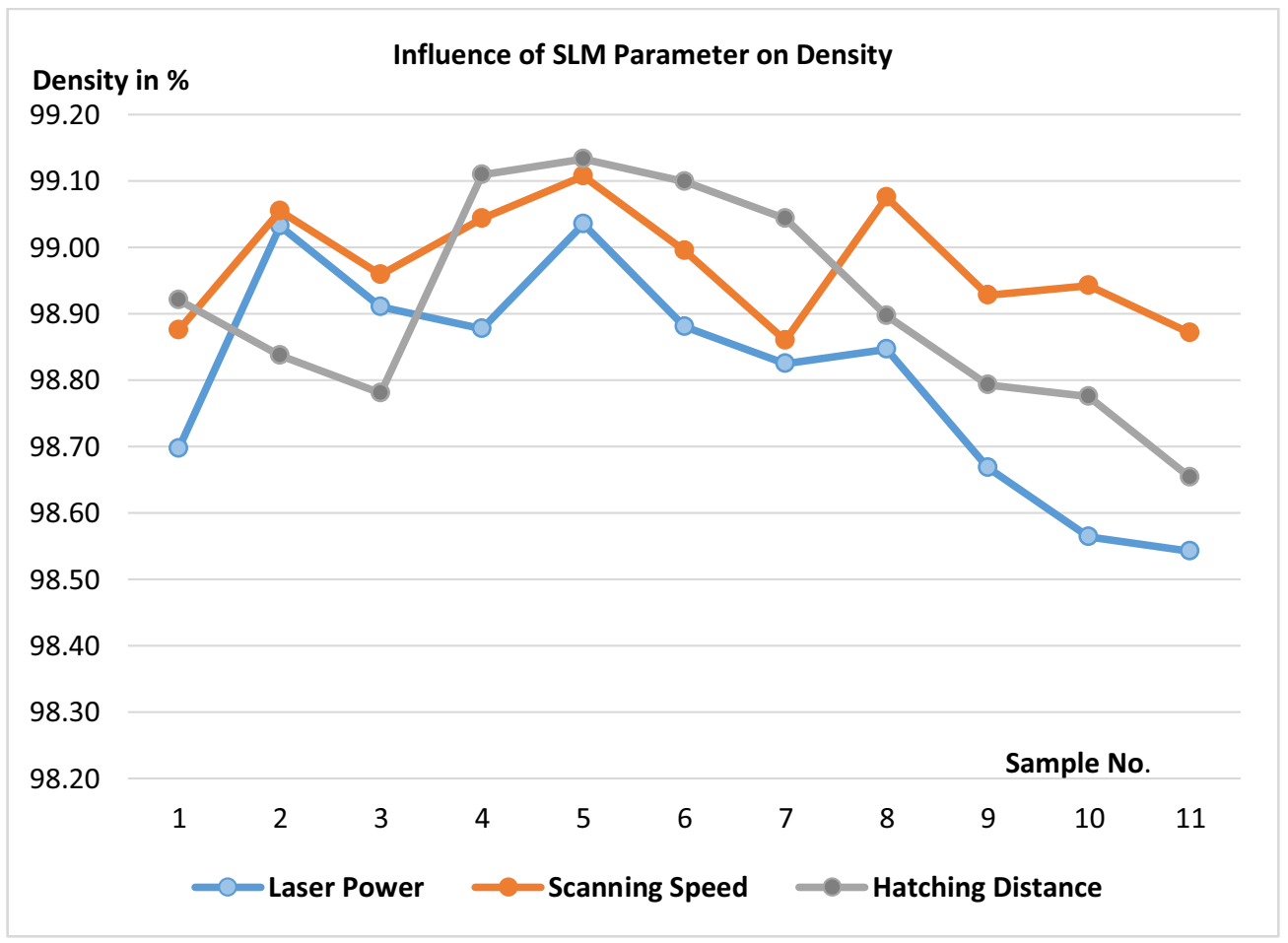

Fig. 5. Density with SLM Parameters (Laser power, Scanning speed and Hatching distance.)

At the variation of laser power from 320 to 380 watts with an interval of 6 watts for each sample and where the scanning speed and hatch distance remain constant at 1650 $\mathrm{mm} / \mathrm{s}$ and $0.13 \mathrm{~mm}$ respectively, the highest density value of $99.07 \%$ occurred at sample No. 5 with the laser power of 350 watts. Meanwhile, at the constant laser power and a hatching distance at 350 watts and $0.13 \mathrm{~mm}$, respectively, with the variation of scan speed of 1550 to $1750 \mathrm{~mm} / \mathrm{s}$ and equal intervals of $20 \mathrm{~mm} / \mathrm{s}$, the density increase slightly to $99.11 \%$. While the values of density measurement with the range of hatching distance from $0.1 \mathrm{~mm}$ to $0.15 \mathrm{~mm}$ by the intervals of $0.05 \mathrm{~mm}$ and remained the laser power and scanning speed constant at 350 watt and $1650 \mathrm{~mm} / \mathrm{s}$ respectively, gave preeminent result of $99.34 \%$ at hatching distance of $0.13 \mathrm{~mm}$.From the trend of the results from experiment, it shows that the optimum value of density occurred at 350 watts laser power, $1650 \mathrm{~mm} / \mathrm{s} \mathrm{scanning}$ 
speed and $0.13 \mathrm{~mm}$ hatching distance, whereby proven by the machine manufacture as the optimum parameters for AlSi10Mg. From the graph presented in Figure 4, it also can be noticed that the minimum value of density occurred at the highest value of each parameter. Whereby high input of the laser power may result, excessive energy density that leading to oxidation and pore formation. Meanwhile the increasing porosity with the increases of the hatching distance is due to the reduces of the intra-layer overlap and the part is held together mostly through interlayer bonding. Differently for the scanning speed effect, where metallurgical pores occurred at a slow scanning speed which the gases trapped inside the molten pool consolidation. Meanwhile keyhole pores formation arisen when the scanning speed is too fast due to rapid solidification of the alloy without completely filling the gaps with molten alloy [5].

\subsection{Mechanical properties}

Hardness is well recognised as a preliminary indication for mechanical properties. By using the Micro-Vickers hardness testing machine, the measurements on 3 test cube samples with dimensions of $10 \mathrm{~mm} \times 10 \mathrm{~mm} \times 10 \mathrm{~mm}$ were conducted at 10 different locations of the top surface ( $\mathrm{x}-\mathrm{y}$ direction) and side wall surface (y-z direction). The mean value of the hardness on both surfaces direction is listed in Table 5 .

Ultimate Strength, Yield Strength and Elongation (\%) results were achieved from the tensile tests according to ASTM E23 standard. Three samples of AlSi10Mg fabricated by SLM were inspected in the $\mathrm{x}-\mathrm{z}$ direction at optimised parameters. The mean values are listed in Table 5 while the stress-strain curve is presented in Figure 5. As the reference and comparision to the current research work, the value of mechanical properties such as Ultimate Strength, Yield Strength and Elongation (\%), Hardness and Impact energy of High pressure die cast (HPDC) alloy A360F, HDPC alloy A360T6 [17] are also listed in the table 5 .

Both HPDC alloys are considered to give the optimum mechanical properties for industrial application. This is the reason to examine the mechanical properties of AlSil0Mg sample fabricated by SLM in the $x-z$ direction for further investigation and practicability in the manufacturing and other industrial applications.

Table 5. Mechanical properties of SLM AlSi10Mg samples and HPDC alloy A360F and A360T6

\begin{tabular}{|c|c|c|c|c|c|c|}
\hline Material & Direction & $\begin{array}{c}\text { Yield } \\
\text { Strength } \\
\text { (MPa) }\end{array}$ & $\begin{array}{c}\text { Ultimate } \\
\text { Tensile } \\
\text { Strength } \\
\text { (MPa) }\end{array}$ & $\begin{array}{c}\text { Elongation } \\
\text { at Break } \\
\mathbf{( \% )}\end{array}$ & $\begin{array}{c}\text { Hardness } \\
\text { (HV) }\end{array}$ & $\begin{array}{c}\text { Impact } \\
\text { energy } \\
\text { (J) }\end{array}$ \\
\hline AlSi10Mg & $\mathrm{X}-\mathrm{Z}$ & $242 \pm 5$ & $412 \pm 2$ & $6.34 \pm 0.3$ & 139 & $2.5 \pm 0.5$ \\
\hline A360F[17] & - & $160-185$ & $300-350$ & $3-5$ & $95-105$ & $2.5 \pm 3.0$ \\
A360T6[17] & - & $285-330$ & $330-365$ & $3-5$ & $130-133$ & \\
\hline
\end{tabular}

Both values of Vickers hardness measurements on the top surface (x-y direction) and side wall surface (y-z direction) are greater than HPDC alloy A360F and A360T6. The Vickers hardness values were improved $32 \%$ for the top surface (x-y direction) and $42 \%$ for the side wall surface (y-z direction) compared to HPDC alloy A360F. On the other hand, the Vickers hardness value were also improved by a small margin of $4 \%$ for the top surface (x-y direction) and $12 \%$ for the side wall surface (y-z direction) as compared to HDPC alloy A360T6. The yield strength value of the AlSi10Mg samples produced by SLM is $31 \%$ higher compared to HPDC alloy A360F, but $27 \%$ lower from the HDPC alloy A360T6. Whereas the value of the ultimate tensile strength of SLM AlSil0Mg samples is 
higher when compared to the both HPDC alloys. The elongation at break is nearly $2 \%$ higher as compared to the HPDC alloys in both conditions. Although the strength and hardness values were higher than the HPDC alloys, still the result from the charpy impact energy of this experiment is comparable to both HPDC alloys. This experiment result trend has also been proven by K.Kempen et al [18] in his experiment using the same material processed through SLM although the samples were fabricated in different scanning stratiges and $\mathrm{x}-\mathrm{y}$ and $\mathrm{z}$ building directions.

Overall, from the experimental results, it can be observed that the AlSi10Mg samples produced by SLM in X-Z direction possessed higher mechanical properties as compared to the HPDC alloy A360F and HDPC alloy A360T6. It can be concluded that A1Si10Mg product produced by SLM can be practically employed in the manufacturing and other industrial applications.

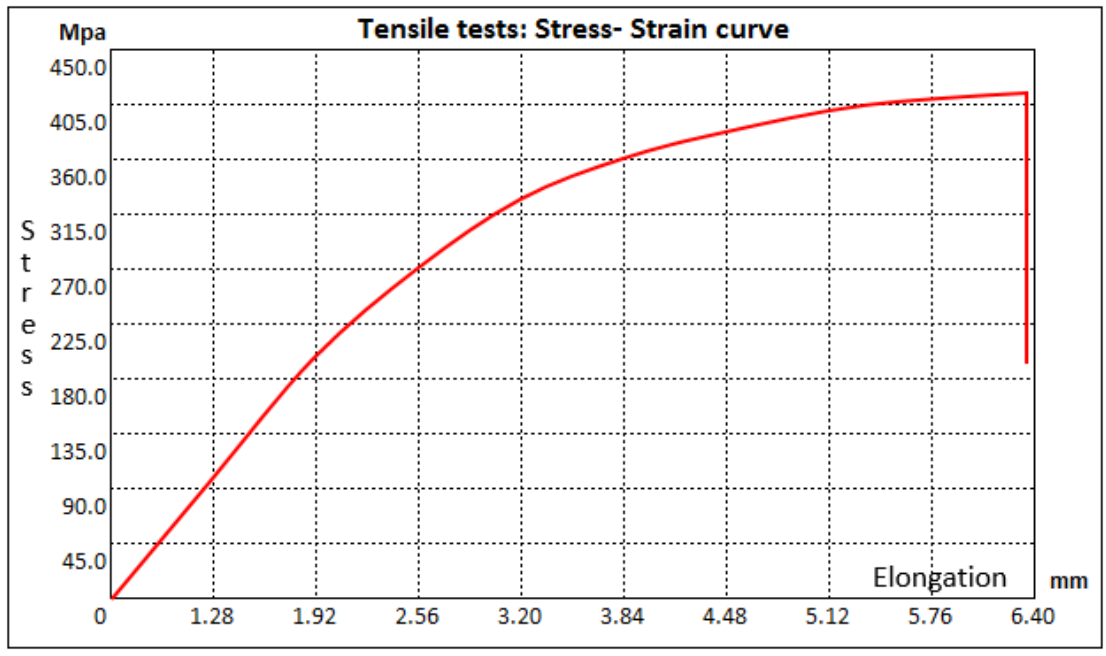

Fig. 5. Stress-Strain curves for SLM AlSi10Mg Samples built along X-Z direction

\section{Conclusion}

After characterisation and analysis of the powder size, morphology and chemical composition through to the assessment of mechanical properties of AlSi10Mg SLM as fabricated samples, it can be concluded that:

- The SLM process is controlled by the set of parameters involved in the process such as laser power, scanning speed, hatching spacing, and layer thickness. Furthermore, with the optimised application of scanning strategy will increase the part density from 99.34 $\%$ to $99.8 \%$.

- The OFAT method has been used to evaluate the influence of process parameters on the porosity of SLM processed AlSil0Mg shows the trends of porosity in the SLM fabricated samples.

- As a comparison of the properties of a the HPDC alloy A360F to the HDPC alloy A360T6, AlSi10Mg SLM samples demonstrated slightly higher values of hardness, yield strength, ultimate tensile strength and elongation at break, while for the Charpy impact energy test, there is comparable, although with a slightly lower value and can 
be concluded that it can be practically employed for varieties industrial applications even in very challenging like aerospace, medical and manufacturing sectors.

- Upon observation of the part density and mechanical properties of the SLM processed AlSi10Mg samples, it can be determined that the samples possessed a comparable and even better mechanical properties to those of conventionally HDPC A360F and HDPC A360T6 alloys although without any comprehensive post processing methods.

This research work is financially supported by Research Innovation Commercialisation and Consultancy Management (ORICC), University Tun Hussein Onn Malaysia (UTHM).

\section{References}

1. C.Y. Yap, C.K. Chua, Z.L. Dong, Z.H. Liu, D.Q. Zhang, L.E. Loh, S.L. Sing, Appl. Phys. Rev., 2(4), (2015)

2. X. Yan, P. Gu, CAD Comput. Aided Des., 28(4), 307 (1996)

3. N.P. Karapatis, J.P. Van Griethuysen, R. Glardon, Rapid Prototyping J., 4(2), 77 (1998)

4. K.V. Wong, A. Hernandez, ISRN Mech. Eng., 16, (2012)

5. N.T. Aboulkhair, N.M. Everitt, I. Ashcroft, C. Tuck, Additive Manufacturing, 1, 77 (2014)

6. D. Manfredi, F. Calignano, M. Krishnan, R. Canali, E.P. Ambrosio, E. Atzeni, Materials, 6(3), 856 (2013)

7. E. Louvis, P. Fox, C.J. Sutcliffe, J. Mater. Process. Tech., 211(2), 275 (2011)

8. Y. Wang, J. Bergström, C. Burman, Mater. Sci. Eng. A, 513, 64 (2009)

9. E. Brandl, U. Heckenberger, V. Holzinger, D. Buchbinder, Mater. Des., 34, 159 (2012)

10. B. Vandenbroucke, J.P. Kruth, Rapid Prototyp. J., 13(4), 196 (2007)

11. D. Manfredi, F. Calignano, E. P. Ambrosio, M. Krishnan, R. Canali, S. Biamino, M. Pavese, E. Atzeni, L. Luliano, P. Fino, C. Badini, La metallurgia italiana, 105(10), 15 (2013)

12. M. Rivette, P. Mognol, and J.Y. Hascoet, Rapid Prototyp. J., 19(2), 77 (2013)

13. A. Simchi, Mater. Sci. Eng. A, 428(1), 148 (2006)

14. S. Menargues, E. Martín, M.T. Baile, J.A. Picas, Mater. Sci. Eng. A, 621, 236 (2015)

15. J. Rajabi, G. Branch, J. Rajabi, E. Alibeiki, G. Branch, M. Nekoei, S. Branch, M. Rajabi, G. Branch, M. R. Meschian, M. Branch, Academic Research International, 2(3), 114 (2012)

16. ASTM E23 - 16b, Standard Test Methods for Notched Bar Impact Testing of Metallic Materials, (ASTM Standards 2002)

17. L. Roger, Technical data sheets for heat treated aluminium high pressure die castings, (CSIRO Light Metals Flagship Technical data 2008)

18. K. Kempen, L. Thijs, J. Van Humbeeck, J.P. Kruth, Phys. Procedia, 39, 439 (2012) 